\title{
Economics, Input Use Efficiency, Yield Gap and Constraints Analysis of Sugarcane Farming in West-Champaran, District of Bihar: Micro Perspectives
}

\author{
Shiva Pujan Singh ${ }^{1}$, Md. Minnatullah ${ }^{2}$, Meera Kumari ${ }^{3}$ and Bipin $\mathrm{Saw}^{4}$ \\ ${ }^{1}$ Deptt.of Agricultural Economics, Sugarcane Research Institute, RPCAU, Pusa, India \\ ${ }^{2}$ Sugarcane Research Institute, RPCAU, Pusa, India \\ ${ }^{3}$ Department of Agricultural Economics, BAU, Sabour, Bihar, India \\ ${ }^{4}$ Department of Agricultural Economics, RPCAU, Pusa, India \\ *Corresponding author
}

\begin{tabular}{|l|}
\hline K e y w o r d s \\
Sugarcane cost, \\
Revenue, Resource \\
use efficiency, \\
Yield gap and \\
constraints analysis, \\
Bihar
\end{tabular}

\section{A B S T R A C T}

\section{Introduction}

Sugarcane occupies a very prominent position in the country economy. It is the second largest agro based industrial crop of the state 97 is a wonder crop it provide sugar for human being as a sugar of energy, ethanol as a fuel for transport system, electricity both for 
industry and agriculture and bio compost to enrich the soil apart from other several byproducts/co-products. Sugarcane is cultivated in around 5.28 million hectares producing 336.9 million tons of cane with average productivity of 63.70 tonnes per hectare (Indian sugarcane 2017) Indian is also largest consumer of sugar $(15.93 \%)$ of the world and $7^{\text {th }}$ largest exporter of sugar $(2.80 \%)$ to 113 countries of the world.

Bihar is an important sugarcane growing state in the country with its area of 0.304 , million hectares with a share of 5.58 percent. The average production of Bihar was18.28 million tons which was4.68 percent of the total production of the country with yield level of 60.15tons per hectare 2018-19.In Bihar the major sugarcane growing districts are WestChamparan. East Champaran, Gopalganj, Sitamarhi, Siwan and Samastipur district respectively. Which do not only account for nearly 70 percent cane area but 60 percent of annual cane production of the state.

Sugarcane is an important industrial crop of the North Bihar. It has dominated the farming system in this region for along time. Even at present about $30 \%$ of the total sugarcane produced is utilized for manufacturing of a jaggery, Khandsari and also for seed, feed, chewing fresh juice for drinking and vinegar etc. in Bihar. Therefore, to explain the possibilities of raising sugar production and farm income in this region, West-Champaran in the major sugarcane growing district contributing 48.0 percent of the total sugarcane area of the state till 1960. Bihar used to contribute around $30 \%$ of total sugar production with 33 sugar factories out of 56 total in India. There are 28 sugar mills in Bihar out of which 17 are sick and closed 11 are working in private sector. Out of 11 operating sugar mills four are in the WestChamparan district. Bihar will have to produce at least one million tonnes of sugar annually to make itself sufficient with per capita consumption of $12 \mathrm{~kg}$ only. However with the increasing cost of inputs, the margin in sugarcane cultivation has been squeezed in spite of increasing in FRP. Hence, this study becomes crucially important for the farmers to know their production cost. The cost of production and returns from sugarcane varies from region to region and from one category to farmers to another.

The specific objectives of this study include to asses the economics of sugarcane production. To determine the factors affecting sugarcane production. To study the source of yield gaps in sugarcane cultivation. The identify the significant constraints in sugarcane cultivation and suggest the suitable policy measures to improve the sugarcane production and productivity.

\section{Sampling and data collection}

West-Champaran is the highest sugarcane growing districts of the state. Sugarcane is grown up as a major field crop by majority of the farmers in the district and had a maximum area of irrigated sugarcane cultivation. Therefore this district was purposively selected for the study.

The study was confined to samples of 68 sugarcane farmers from four village of two blocks from one leading district viz. West Champaran with respect to sugarcane area, through personal survey method with the help of multi stage random sampling technique. In each selected village farmers were classify into three size groups viz. marginal $(<1.0 \mathrm{ha})$ small, (1.0-2.0 ha), and medium large (>2.0 ha) categories based on their operated land holding.

\section{Analytical frame work}

A sample percentage analyses was employed 
to identify the cost and return of sugarcane cultivation for the selected sample farmers. Production function analysis was used for determining the efficiency of various resources used in the process of production. The Cobb-Douglas production function was used due to higher value of coefficient of multiple determinations obtained.

The methodology developed by the International Rice Research Institute (IRRI) was used to study the yield gaps (Particularly more emphasis is given to yield gap-II). The data on various aspects of sugarcane production on farmer's field, demonstration plots and research station plots were collected with the help of pre-tested schedules.

\section{Production function}

$Y=a^{X_{1}^{b_{1}}} X_{2}^{b_{2}} X_{3}^{b_{s}} X_{4}^{b_{4}} X_{5}^{b_{5}} X_{6}^{b_{6}}+u_{i}$

$\mathrm{b}_{1}=$ Regression coefficient

$\mathrm{u}_{\mathrm{i}}=$ Error term $(\mathrm{i}=1,2 \ldots . . \mathrm{n})$

Where, $y$ is the yield of sugarcane (tons), $X_{i}$ is the human labour (manday), $\mathrm{X}_{2}, \mathrm{X}_{3}, \mathrm{X}_{4} \ldots \ldots \mathrm{X}_{6}$ denotes the cost of seed, manure and fertilizers, irrigation cost, tractor cost and plant protection chemicals respectively.

\section{Resource use efficiency}

Resource use efficiency which may be defined as the ability to fetch maximum out put per unit of resources properly addressed in achieving optimal production.

The estimated coefficient of significant independent variables was used to compute the marginal value products (MVP).

$\mathrm{MVP}_{\mathrm{i}}=\mathrm{B}_{\mathrm{i}} \frac{\overline{\bar{y}}}{\overline{\bar{x}}_{\mathrm{i}}} \times \mathrm{P}_{\mathrm{y}}$

Here,

$\mathrm{MVP}_{\mathrm{i}}=$ Marginal value product of the $\mathrm{i}^{\text {th }}$ input

$\bar{y}=$ Geometric mean of the value of out put (in rupees)

$\bar{x}_{2}=$ Geometric mean of the $i^{\text {th }}$ input (in rupees)

$\mathrm{B}_{\mathrm{i}}=$ Estimated co-efficient (or) production elasticity with respect to $\mathrm{x}_{\mathrm{i}}$ input.

$\mathrm{P}_{\mathrm{y}}=$ Price of out put

\section{Garrett's ranking technique}

The opinions survey of farmers sample about the various constraints in sugarcane production was collected and analyzed using Garrett's ranking technique. The ranks given by each respondent were converted into percent position by using formula.

$$
\text { Percent position }=\frac{100 \times\left(R_{i j}-0.5\right)}{N_{i}}
$$

Where,

$R_{i j}=$ Rank given to $\mathrm{i}^{\text {th }}$ constraints by the $\mathrm{j}^{\text {th }}$ individual and

$\mathrm{N}_{\mathrm{j}}=$ Number of constraints ranked by the $\mathrm{j}^{\text {th }}$ individual.

The estimated percent positions were converted into scores using Garrett's table. The mean score values estimated for each factor were arranged in the descending order. The constraints with the highest mean value was considered as the most important one and the others followed in that order.

\section{Result and Discussion}

\section{Costs and returns in sugarcane production}

The recent experience confirms that faster growth in agricultural production is necessary for the overall economic development. Increase in agricultural production is continuously possible by increasing the productivity of land. The productivity of level 
depends on the optimum allocation of resources, which are always being considered either of scarce or costly and would have a definite impact on the cost and revenue structure of crop farms. It may be noticed that in agricultural production, cost of production refers to the expenditure incurred by the farmers on the various inputs (fixed and variable) to obtain the final produce. The fixed cost includes depreciation, taxes, rent, interest, etc., which results from past commitments of costs already sunk. It is constant over time and does not change with the changes in crop output. On the other hand, there are variable cost viz. cost of human labour (family and hired), machinery power, seeds, manures, fertilizers, plant protection chemicals etc. which are directly linked up with output. This would be an important cost which determine how much and what is to be produced. Therefore, it is the variable cost, based on which the major cropping decisions are taken at farm levels.

The estimated cost and revenue particulars of sugarcane production pertaining to the different farm level data collected farm the sample farmers of four villages of two blocks of West Champaran district is furnished from Table -1 .

The data furnished in table- 1 indicate that an average sugarcane cultivating farmers in the area spent 26.14 percent of the total operating cost, on hired human labour, 1.08 percent on bullock power, 16.55 per cent on machinery used for different operations. Out of total operational cost, shared of material cost seed (setts), fertilizer, plant protection chemicals and irrigation charges was 25.77 percent, 19.11 percent, 4.56 percent and 6.77 percent respectively. In other words of the cost constituents, the share of hired labour was recorded to be the maximum(26.14\%) indicating the fact that sugarcane production in the area is largely depend upon hired labour. Human labour utilization was maximum in planting; inter cultivation, followed by harvesting and transportation cost of seed occupied the second important position in the cost of cultivation of sugarcane. Among the various categories of farms through the average trends in the use of factor inputs continue in all categories of farms, there had been a significant difference observed between farms, especially in the use of machine power. From the point of view of net return, this tended to increase with farm size. The net return per hectare amounted tobe Rs. 101605, Rs. 125240 and Rs. 139902 on marginal, small and medium large farms respectively. The higher net returns on medium large farm due to higher yield and the higher price revel by these farmers. The crop productivity was highest 77 t/ha under medium -large size farm and lowest 65 t/ha in marginal farm condition.

\section{Production function estimates in cultivation of sugarcane}

For sugarcane growers of West-Champaran:-

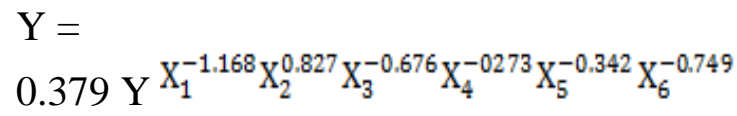

The estimated resources use efficiency in sugarcane production in furnished in table -2 . The $\mathrm{R}^{2}$ value was found to be more than 0.945 which indicate that 94 per cent of the variations in sugarcane yield were influenced by the explanatory variables included in the modes. The human labour utilized in sugarcane cultivation was negative and nonsignificant in some cases may be due to timely. Unavailability of human labour, the utilization of seed, irrigation cost and plant protection chemical were positive and significant for all the farm size. The significant and positive co-efficient indicates that increase in inputs such as irrigation, seed cost and plant protection chemicals would 
increase the yield of sugarcane by 0.27 per cent, 0.82 per cent and 0.74 per cent respectively.

The contribution of tractor cost in gross return was positive but non-significant. The manure and fertilizers utilize in sugarcane crop enhancing efficiency, these inputs co-efficient were negative and significant. It was reported during field investigation that most of the sample, farmers used excess quantity of manures and fertilizer than the recommended level. Return to scale (sum of the production elasticity) was found more than one (1.347) exhibit increasing return to scale indicates that simultaneous increase of one percent in factor of production yield, increase more than one percent in gross return.

\section{Comparison of marginal value product (MVP) with acquisition cost}

The MVP of all the resources were compared with their corresponding acquisition cost i.e. the cost price plus interest and the differences between the two were tested statistically for their significant with the help of t-test.

The (Table-3) represents that the marginal value product of seed, irrigation and tractor cost is significantly higher than its acquisition cost, it indicates that there is sub-optional use of the seed, irrigation and tractor cost. Therefore need to increase the level of seed, irrigation and tractor cost to achieve maximum return.

The MVP of manure and fertilizers was significantly lower than the requisition indicating cost, that there was excess use of these resources than the recommended level, there was need to decrease use of manure and fertilizers application to achieve maximum return.

\section{Source of yield in sugarcane}

Among the different source contributing to the yield gap, the difference in technique of production between the farmer's field and the demonstration plot (yield gap II) was turned out to be highest 28.51 per cent in the marginal farms and the lowest 16.41 per cent in large farms (Table-4), hence due to better economic conditions, large farmers have taken up better and timely crop management practical's like land preparation, sowing, spacing timely application of recommended dose of plant nutrients and plant protection chemicals. The table 5 also revealed that the input use differences contributed about 33 per cent on the overall category of farmer's field.

Thus, deviation from the recommended package of practices on farmer's fields adversely affected the yield performance of sugarcane. Hence, efforts on the parts of the extension agencies to persuade the farmers to accept, adopt and real the full benefits of the recommended technology in an urgent need in the present condition.

In constraints:

The constraints being faced by the sample, sugarcane growers were ranked using Garrett's ranking technique and the results are given in Table-6. The major constraints were unavailability of farm laboures during peak period due to reason that high wages is one hand and another most of the laboures work under MNREGA scheme. The second most significant constraints were unavailability of fertilizer on time (76.92) average score in Garrett's ranking, identified. The other constraints were infestation of pest and disease (77.0) unavailability of planting material (70.20) and unavailability of loan on time (61.10) and high cost of plant protection chemicals (56.75) respectively. 
Table.1 Estimated cost and revenue of sugarcane cultivation in West-Champaran district (in Rs/ha)

\begin{tabular}{|c|c|c|c|c|}
\hline \multirow[t]{2}{*}{ Cost/revenue particulars } & \multicolumn{4}{|c|}{ Farm size in ha. } \\
\hline & $\begin{array}{c}\text { Marginal } \\
(<1.0)\end{array}$ & $\begin{array}{c}\text { Small } \\
(1.0- \\
2.0)\end{array}$ & $\begin{array}{l}\text { Medium - } \\
\text { large } \\
(>2.0)\end{array}$ & All \\
\hline Area under crop (in ha.) & 3.31 & 11.15 & 24.30 & 38.70 \\
\hline \multirow{2}{*}{ Cost of hired human labour } & 14792 & 14915 & 16209 & 15716 \\
\hline & $(23.88)$ & $(23.30)$ & $(27.90)$ & (26.14) \\
\hline \multirow[t]{2}{*}{ Cost of Bullock power } & 718 & 793 & 580 & 653 \\
\hline & $(1.16)$ & $(1.23)$ & $(0.99)$ & $(1.08)$ \\
\hline \multirow[t]{2}{*}{ Cost of machine power } & 15054 & 15168 & 6863 & 9952 \\
\hline & $(24.30)$ & $(23.70)$ & $(11.81)$ & $(16.55)$ \\
\hline \multirow[t]{2}{*}{ Cost of seed (setts) planting } & 14390 & 15276 & 15744 & 15494 \\
\hline & $(23.22)$ & $(23.87)$ & $(27.10)$ & $(25.77)$ \\
\hline \multirow{2}{*}{ Cost of fertilizers } & 9201 & 9605 & 12669 & 11492 \\
\hline & $(14.85)$ & $(15.00)$ & $(21.80)$ & (19.11) \\
\hline \multirow{2}{*}{ Cost of plant protection chemicals } & 2631 & 2724 & 2773 & 2746 \\
\hline & $(4.24)$ & $(4.25)$ & $(4.77)$ & $(4.56)$ \\
\hline \multirow[t]{2}{*}{ Cost of irrigation charges } & 5163 & 5516 & 3255 & 4069 \\
\hline & $(8.33)$ & $(8.62)$ & $(5.60)$ & $(6.77)$ \\
\hline \multirow[t]{2}{*}{ Cost of $A_{1}$ (operating cost ) } & 61949 & 63997 & 58093 & 60122 \\
\hline & $(100.00)$ & $(100.00)$ & $(100.00)$ & $(100.00)$ \\
\hline Interest on working capital & 3886 & 4006 & 3495 & 3675 \\
\hline $\begin{array}{l}\text { Depreciation cost on implements and farm } \\
\text { building }\end{array}$ & 4160 & 6843 & 18644 & 9882 \\
\hline Cost A & 69998 & 74846 & 80232 & 73679 \\
\hline Cost $A_{2}\left(A_{1}+\right.$ Rent paid for leased in land $)$ & 61949 & 63997 & 58093 & 60122 \\
\hline Cost $\mathbf{B}_{1}\left(\mathbf{A}_{1}+\right.$ interest on capital assets) & 63719 & 66953 & 75400 & 71974 \\
\hline Cost $B_{2}\left(B_{1}+\right.$ RVOL $)$ & 85678 & 88901 & 97345 & 93921 \\
\hline Cost $C_{1}\left(B_{1}+\right.$ Family labour $)$ & 96116 & 70305 & 76570 & 74132 \\
\hline Cost $C_{2}\left(B_{2}+\right.$ Family labour $)$ & 91075 & 92253 & 98515 & 96075 \\
\hline Cost $C_{3}\left(C_{2}+10 \%\right.$ of $\left.C_{2}\right) /$ total cost & 100183 & 101478 & 108367 & 105683 \\
\hline Yield (t/ha) & 65.0 & 76.0 & 77.0 & 76 \\
\hline Cost of production (Rs/t) & 1318 & 1170 & 1264 & 1236 \\
\hline Total returns (TR) & 163554 & 189237 & 197995 & 192535 \\
\hline B-C ratio (on operating cost) & 2.64 & 2.96 & 3.41 & 3.20 \\
\hline B-C ratio (on total cost) & 1.63 & 1.86 & 1.83 & 1.82 \\
\hline Net return (on operating cost) & 101605 & 125240 & 139902 & 132413 \\
\hline
\end{tabular}

Source: Survey data (figures in parentheses indicate percentage) 
Table.2 Resource use efficiency is sugarcane production

\begin{tabular}{|c|l|c|c|c|}
\hline SI No. & \multicolumn{1}{|c|}{ Particulars } & $\begin{array}{c}\text { Regression } \\
\text { coefficient }\end{array}$ & Standard error & t-value \\
\hline $\mathbf{1}$ & Human labour (man days ) $\mathrm{X}_{1}$ & -0.168 & 0.219 & -0.767 \\
\hline $\mathbf{2}$ & Seed (Rs.) $\mathrm{X}_{2}$ & $0.827^{* *}$ & 0.498 & 1.66 \\
\hline $\mathbf{3}$ & Manures \& fertilizer (Rs.) $\mathrm{X}_{3}$ & $-0.676^{* *}$ & 0.342 & -1.977 \\
\hline $\mathbf{4}$ & Irrigation cost (Rs.) $\mathrm{X}_{4}$ & $0.273^{*}$ & 0.087 & 3.132 \\
\hline $\mathbf{5}$ & Tractor cost (Rs.) $\mathrm{X}_{5}$ & 0.342 & 0.215 & 1.595 \\
\hline $\mathbf{6}$ & Plant protection chemical (Rs.) $\mathrm{X}_{6}$ & $0.749 *$ & 0.282 & 2.655 \\
\hline $\mathbf{7}$ & Sum of elasticity $\sum b_{i}$ & 1.347 & - & - \\
\hline $\mathbf{8}$ & Intercept & 0.379 & 1.701 & 0.223 \\
\hline $\mathbf{9}$ & Coefficient of multiple determination & 0.945 & - & - \\
\hline
\end{tabular}

Note: $* * *$ and $* *$ indicate significant at $1 \%$ and5\% probability level respectively

Table.3 Comparison of marginal value product (MVP) of the resources with their acquisition cost in West Champaran district

\begin{tabular}{|c|c|c|c|c|c|c|}
\hline \multirow{2}{*}{ Crop } & \multicolumn{5}{|c|}{ Resources } \\
\cline { 2 - 7 } & $\begin{array}{c}\text { Human } \\
\text { labour } \\
\left(\mathbf{X}_{\mathbf{1}}\right)\end{array}$ & $\begin{array}{c}\text { Seed } \\
\left(\mathbf{X}_{\mathbf{2}}\right)\end{array}$ & $\begin{array}{c}\text { Manure \& } \\
\text { fertilizer } \\
\left(\mathbf{X}_{\mathbf{3}}\right)\end{array}$ & $\begin{array}{c}\text { Irrigation } \\
\text { cost }\left(\mathbf{X}_{\mathbf{4}}\right)\end{array}$ & $\begin{array}{c}\text { Tractor } \\
\left.\text { cost } \mathbf{X}_{\mathbf{5}}\right)\end{array}$ & $\begin{array}{c}\text { Plant } \\
\text { chemicals } \\
\left(\mathbf{X}_{\mathbf{6}}\right)\end{array}$ \\
\hline $\begin{array}{c}\text { MVP at } \\
\text { Geometric } \\
\text { mean }\end{array}$ & -2.05 & $10.11^{* * *}$ & $-9.42^{* *}$ & $12.24 *$ & $20.44 *$ & 13.76 \\
\hline $\begin{array}{c}\text { Acquisition } \\
\text { cost (per unit }\end{array}$ & 1.12 & 1.12 & 1.12 & 1.12 & 1.12 & 1.12 \\
\hline $\begin{array}{c}\text { price) } \\
\text { Differences }\end{array}$ & -3.17 & 8.99 & -10.54 & 11.12 & 19.32 & 12.64 \\
\hline Standard error & 0.219 & 0.498 & 0.342 & 0.087 & 0.215 & 0.282 \\
\hline
\end{tabular}

Note: $* * *$ and $* *$ indicate significant at $1 \%$ and $5 \%$ respectively 
Table.4 Yield gap in sugarcane on sample farmers in West Champaran district

\begin{tabular}{|c|c|c|c|c|c|}
\hline \multirow{2}{*}{$\begin{array}{l}\text { Sl. } \\
\text { No. }\end{array}$} & \multirow[t]{2}{*}{ Particulars } & \multicolumn{3}{|c|}{ Size groups } & \multirow{2}{*}{$\begin{array}{c}\text { Over all } \\
N=60\end{array}$} \\
\hline & & $\begin{array}{c}\text { Marginal } \\
\mathbf{N}^{*}=\mathbf{2 0}\end{array}$ & $\begin{array}{l}\text { Small } \\
\mathbf{N}^{*}=20\end{array}$ & $\begin{array}{l}\text { Large } \\
\mathbf{N}^{*}=\mathbf{2 0}\end{array}$ & \\
\hline 1 & Potential yield (Yp) & 150 & 150 & 150 & 150 \\
\hline 2 & $\begin{array}{l}\text { Demonstration yield } \\
\text { (Yd) }\end{array}$ & 92 & 92 & 92 & 92 \\
\hline 3 & Actual yield (Ya) & 65.40 & 75.70 & 76.90 & 73.15 \\
\hline 4 & Yield gap -I (Yp-Yd) & $\begin{array}{c}58 \\
(38.66)\end{array}$ & $\begin{array}{c}58 \\
(38.66)\end{array}$ & $\begin{array}{c}58 \\
(38.66)\end{array}$ & $\begin{array}{c}58 \\
(38.66)\end{array}$ \\
\hline 5 & Yield gap -II (Yd-Ya) & $\begin{array}{c}26.60 \\
(28.51)\end{array}$ & $\begin{array}{c}16.30 \\
(17.72)\end{array}$ & $\begin{array}{c}15.10 \\
(16.41)\end{array}$ & $\begin{array}{c}18.85 \\
(20.92)\end{array}$ \\
\hline 6 & Total yield gap (Yp-Ya) & $\begin{array}{c}84.60 \\
(56.41)\end{array}$ & $\begin{array}{c}74.30 \\
(49.53)\end{array}$ & $\begin{array}{c}73.10 \\
(48.73)\end{array}$ & $\begin{array}{c}76.85 \\
(51.00)\end{array}$ \\
\hline
\end{tabular}

Table.5 Different sources contributing to yield gaps in sugarcane production

\begin{tabular}{|c|c|c|c|c|c|}
\hline \multirow[t]{2}{*}{ Sl. No. } & \multirow[t]{2}{*}{ Source of yield gap } & \multicolumn{4}{|c|}{ Sample farm category (ha) } \\
\hline & & $\begin{array}{c}<1.0 \\
\left(n^{*}=20\right)\end{array}$ & $\begin{array}{l}<1.0-20 \\
\left(n^{*}=20\right)\end{array}$ & $\begin{array}{c}<2.0 \\
\left(n^{*}=20\right)\end{array}$ & $\begin{array}{c}\text { All } \\
\left(n^{*}=20\right)\end{array}$ \\
\hline 1 & Total difference in output (yield gap II) & 28.51 & 17.72 & 16.41 & 20.92 \\
\hline \multirow[t]{7}{*}{2} & \multicolumn{5}{|l|}{ Source of contribution/input use gaps } \\
\hline & (a) Seed & 9.50 & 3.93 & -0.92 & 4.20 \\
\hline & (b) Nitrogen & 0.90 & -10.99 & 4.35 & -0.35 \\
\hline & (c) Phosphorus & -23.48 & -37.02 & -25.20 & -26.45 \\
\hline & (d) Potassium & -32.73 & -8.13 & -53.33 & -49.57 \\
\hline & (e) Plant Protection & 50.89 & 48.81 & 46.29 & 48.72 \\
\hline & (f) Irrigation & 53.25 & 50.17 & 65.44 & 56.52 \\
\hline 3 & Total estimated gap from all inputs & 58.33 & 46.77 & 36.63 & 33.07 \\
\hline
\end{tabular}

Table.6 Production constraints of sugarcane in West Champaran district $(\mathrm{N}=68)$

\begin{tabular}{|c|l|c|c|}
\hline Sl. No. & \multicolumn{1}{|c|}{ Constrains } & Mean scores & $\begin{array}{c}\text { Garret } \\
\text { ranking }\end{array}$ \\
\hline $\mathbf{1}$ & Unavailability of labour during peak period & 80.00 & I \\
\hline $\mathbf{2}$ & Unavailability of fertilizer on time & 76.92 & II \\
\hline $\mathbf{3}$ & Infestation by pests and disease & 77.00 & III \\
\hline $\mathbf{4}$ & Unavailability of planting material in time & 70.20 & IV \\
\hline $\mathbf{5}$ & Unavailability of loan on time & 61.10 & $\mathrm{~V}$ \\
\hline $\mathbf{6}$ & High cost of plant protection chemicals & 56.75 & VI \\
\hline
\end{tabular}


It may be summarized from the study that the economics of sugarcane production in WestChamparan district, the following observations can be accounted for policy planning suitable to this region.

Among the various size group of sugarcane cultivation a comparative advantage has been witnessed for farms in the size group of above 2.0 hectares. Therefore, optimum farm in these areas might full only on these groups.

It is worth pointing that the expenditure on hired human labour was recorded to be the highest among all operating costs for sugarcane cultivation in the area.

Seed planting/seed cost, being a basic input recorded to be an average of about 25.7 per cent for sugarcane.

The cost of chemical fertilizers and plant protection chemicals was found on the rise for large farmers while higher proportion of irrigation cost was witnessed for smaller size farms.

The net return per hectare and $\mathrm{B}-\mathrm{C}$ ratio on operating cost was found highest Rs. 1,39,202 and 3.41 for larger farms respectively.

The study has shown that inputs such as planting materials (seed sett), irrigation and plant protection chemicals have positive and significant influence on the yield of sugarcane crop.

The poor source of irrigation and labour shortage in pick season was found significant constraints/problem in this region.

The farmer's field yield obtained are considerable lower than those of recorded in the demonstration plots. Therefore, there is need to know the different yield gaps between the farmer's fields and the demonstration plots.
The problem of un-availability of labour may be addressed by using low cost machineries and implements.

The study was suggested that to bridge this yield gap farmers should be motivated through visit to progressive farmers field and organizations of field demonstration, seminars and other communication means to use the recommended level of inputs and improved variety of seeds to enhanced the productivity of sugarcane in the state.

\section{References}

Ahmad Nasim, Sinha, D.K., Singh, K.M. Mishra, R.R. and Singh, Shiva Pujan (2018). Resource use efficiency in sugarcane production in Bihar (India): A stochastic frontier analysis. An International Referred. Peer Reviewed to Indexed Jr. in Science, Agricultural and Engineering, ISSN 2277-7601, V(8), April: 130-131.

Goswami, S.N., Chaturvedi, A and Gawande, R.S (2012). Economics and resource use efficiency of rice farming in Gondia district of Maharashtra. Agricultural situation in India 1485 Agri/2012-12A.: 521-527.

Saravanan, K., S., Parvati (2015).An Analysis of cost and returns of sugarcane production in Krishnagiri District of Tamil Nadu. International Journal of Research2(2): 378-384.

Karthick, V.Alagumani, T. and Amarnath, J.S. (2013). Resource use efficiency and technical efficiency of turmeric production in Tamil Nadu-A stochastic frontier approach. Agricultural Economics Research Review 26(1): 109-114.

Rama Rao, I.V.Y., (2012). Efficiency, yield gap and constraints analysis is irrigated vis-à-vis rain fed sugarcane in north coastal zone of Andhra Pradesh. Agricultural Economics Research 
Review 25(1):167-171.

Saravanan, A (2016). Analysis of cost and returns of sugarcane production is Erode district of Tamil Nadu. Indian Journal of Economics and Development 4(8):1-4.

Saw Bipin, Singh Shiva Pujan, Sharma Amardeep and Ahmad Nasim (2020). Cost and returns of sugarcane production: a micro level study of Samastipur and Begusarai district of Bihar. International Journal of Chemical studies 8(2): 1548-1552.

Singh Shiva Pujan, Singh, H.P. Kumari,
Meera, Minatullah, Md. Chand, $\mathrm{H}$ and Kumar Balwant (2018). Economic analysis of production resource use efficiency and constraints analysis of sugarcane cultivation in East Champaran district of North Bihar. International Jr. of current Microbiology and applied sciences ISSN: 2319-7706 V(7): 512-518.

Tripathi, R.S., Raju, R and Thimmappa, K., (2013). Impact of zero tillage on economics of wheat production in Haryana.

\section{How to cite this article:}

Shiva Pujan Singh, Md. Minnatullah, Meera Kumari and Bipin Saw. 2020. Economics, Input Use Efficiency, Yield Gap and Constraints Analysis of Sugarcane Farming in WestChamparan, District of Bihar: Micro Perspectives. Int.J.Curr.Microbiol.App.Sci. 9(10): 29852994. doi: https://doi.org/10.20546/ijcmas.2020.910.360 